\title{
REAL SCENARIO OF SOCIAL MEDIA AGENCY ACTIVITIES AND PROBLEMS FACED BY THEM
}

\author{
Mr.G.Sivaraja, \\ Assistant Professor, \\ Department of Business Administration, \\ Saraswathi Narayanan College, \\ Madurai, Tamilnadu, India
}

\begin{abstract}
Marketing is a field which always have a boom in Industries. It plays a major role in Industries since it promotes each and every product of them. As of now, online marketing is the easiest way to reach customer and interact with them. It is quite possibly achieved via websites and email.

This paper deals with the traces of online marketing and very much into social media marketing. Social media marketing seems easy to pronounce but hard to work with, until success is tasted.

What are the problems involved in social media platform and ways to overcome are clearly labelled in this paper. So before who wants to go for social media marketing, can look into this paper and organise the facts in hand.
\end{abstract}

Keywords: Online and Social media marketing, Agencies and Activities, Problems and ways to overcome.

\section{INTRODUCTION}

\section{Online Marketing}

It is one of the types of advertising through web. It is a promotional technique of products shared via social media, emails, blogs, etc. Since everybody has started using internet, this is the shortest and less expensive method of attracting customers.

\author{
Ms. S.Thilagavathi, \\ Assistant Professor, \\ Department of Commerce, \\ Saraswathi Narayanan College, \\ Madurai, Tamilnadu, India
}

The key areas or strategies in Online marketing are Social media, Website, Audio Video, SEO, Email, Affiliate, Banner, Analysis and Rating. Online marketing involves system and tools to make human work easier. The advantages of this marketing are less human work, low cost, new customers and profit generation.

Image.No. 1

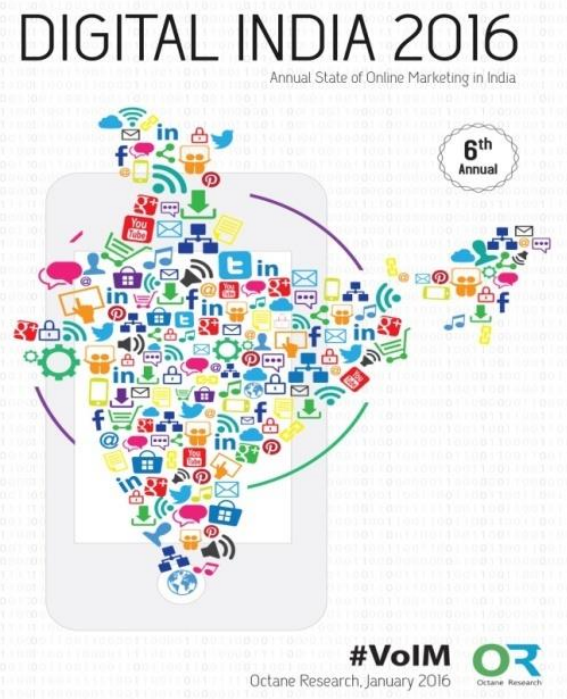




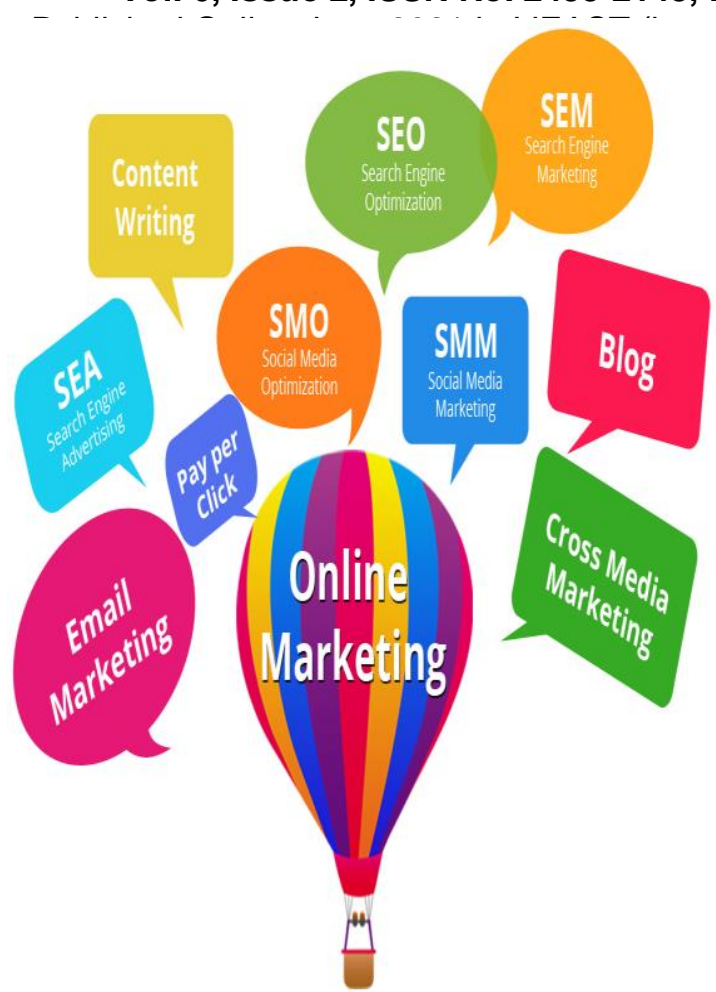

Image.No. 2

Source 1:

https://www.emphatictechnologies.com/onli ne-marketing.php

Source 2:

http://octaneresearch.in/research/digitalindia-state-of-online-marketing-in-india$\underline{2016 /}$

Image No.1 clearly shows the elements that construct an online marketing

Image No. 2 shows how India is looking with the usage of social media platforms

Let's dive into social media topic, the agency, problems and solutions in the upcoming draft.

\section{SOCIAL MEDIA MARKETING (SMM)}

The awareness of social media nowadays is high because of the existence of mobile, laptops, etc. //www.ijeast.com)

Social media marketing is the process of creating, writing and posting own thoughts or videos on social media platform for promoting products or business.

To begin with, a starter kind of social media marketing some agencies are helping out. Here is the list of steps that agency offers to the starters

\section{SMM AGENCIES AND ACTIVITIES}

Agencies are the bodies who work for their clients in reaching their goals such as bring their web on top and advertising their products in a creative manner. There are more than 700 agencies in India approximately which includes Mudra group, ADS, Blowhorn, Indeed, Social Cubicle, Xoom, Webguruz, Iglobe, etc.,

Usually each and every agency divides their work as Internal and External.

Internal:

1. Create Policies

2. Create Profiles

3. Create Strategy

4. Campaigns

5. Social Engagement

6. SEO

7. Auditing

8. Publishing

External:

9. Customer Support

10. Competitor Analysis

\section{PROCEDURES IN BOTH INTERNAL AND EXTERNAL ACTIVITIES}

Internal activities are conducted inside the agency and vice versa are the external activities.

1. Create Policies

Every agency has its own privacy policy and terms of use of its products or service. Similarly, a social media policy declared how an agency or its employees should 
conduct themselves on social media. This helps the business and employees behave responsibly.

2. Create Profiles

Agency creates an enhanced and unique profile for businesses that customers can connect and do interact. It understands the industry under which the clients business comes. Also it checks which social channels is best suited for the business because every channel is unique on its way. Examples for social channels are Face book, Locanto, Instagram, etc.

3. Create Strategy

An Agency knows that starting things without strategy leads to a blind route. So they first conduct an audit of the existing social media, learn the business competition, and then they design a clear strategy. They list out the content and check frequency of publishing, later on they calculate on how much spend to make sure a good ROI.

4. Social Media Campaigns Agencies help the client companies to run campaigns. Social media campaigns differ from the technique of social profiles. Social media campaigns have a specific objective through which they start the process. For instance, it can be brand awareness or creating more followers. To run a campaign successfully, an agency are in need of an in-house expertise.

5. Social Engagement

An agency works for more than one company at a time. They hand many profiles on day today life. They keep managing the responses those flows in different social media. They count the number of likes, followers or read the comments so that they can keep a track on the client companies. Since an agency has to look after many clients, social media engagement software would be useful to them to handle everything.

6. SEO
A SEO normally works in bringing the client companies name on top during a Google search. An Econsultancy survey tells that $82 \%$ of agencies have integrated their SEO with the social media for the benefits of client companies. Eventhough Google has said that it does not matter social signals in search ranking, agencies does not stop to stress the significance of social signals. Agencies are doing this is to ensure they get high engagement.

7. Auditing

The process of identifying, measuring and analyzing the social media presence and suggesting ways to fix issues in existing strategy or come up with new strategy or a distinctive on is called the Auditing process of an agency. For such analysis, social media reporting software has come.

8. Publishing

On a mutual agreement, the agency and client companies agrees to posts contents for every social channel. Agency do research and analyze many media content across the industries where your business fits in. A good social media app can help in achieving this.

9. Customer Support

The more the customer talks about the company, the more they reach. Customers should feel it was a wow-full experience. The latest kind of marketing is social customer care. When a company handles customer service through social channels, it amplifies its brand's social presence. Social media agencies offer to provide social customer support as one of their services. It is important to understand that whatever happens on social media, the world sees it. People can see how a company responds and if done right, the company gets a lot of positive attention. It is considered to be a highly important service that an agency can offer. 
10. Competitor Analysis Agencies try to acquire information about their competitors and how they perform in the market. Each and every agency can learn from their competitor's failure and success. Like other services, this too has reporting software that provides details about the competitors.

\section{PROBLEMS WITH THE MEDIA AGENCIES}

1. Getting adapted slowly

We are living in a digital world now. This digitalization started changing things in every aspect of the marketing world. So there is no time for the marketers to understand to which area they should get adapted to. This takes a bit of time. However they need to learn faster and get adapted quickly to stay on top positions. Numerous analytics tools have come, so much more opportunities for the expertise to get adapted. Marketers once were in critical situation of losing data. But now they have tools for everything to prevent data loss situations. Agency can recover data through recovery software. They are plenty of such available in the market. But damaged data like audio, video, image can cause serious trouble to the agencies.

2. No questions raised

If agencies don't listen to their client companies, then there would be a problem arising for sure. Good agencies listen and ask questions to their clients in order to keep every work on track. Even though tools are present, getting the answers directly from the clients gives a warm feeling. Asking questing at the right time also gives a relief to the agency from fear, stress, conflicts, etc.

3. Same content across channels

There are so many different media channels available but that doesn't mean they are helpful to the agencies. Having only two or three media and posting contents there would also create worse situation. Customers expect more information and good interaction in which ever platform they interact with the agency. Agencies should deliver communication differently to different customers. Agencies should choose only the channels that are suitable. Communicate the message clearly, if not audience will go confused and they will turn against the agency. Post unique contents across all the channels, that make the agency stand on top position always.

4. Budget issue

This is considered to be an important issue. For an instance, if the agency has done the work perfectly and the client cuts a little percentage of pay. Decide the budget in advance and have a margin always in hand. Do not let the clients to cut the percentage for the good work that have been delivered. Keep the clients informed in advance so at the end there wouldn't be any controversies. Ask the clients about their budget also before starting a project. If everything matches, then the agency can move their coin forward.

5. Lack of Unique Selling Point In day today scenario, we could see many agencies are struggling to determine unique selling point. Consumers have plenty of options to access brands than before. This creates a tough thinking to the agency and agency literally feels it's impossible to go unique. Agency can provide same service but the strength lies in finding unique selling point.

Remember a unique selling creates the conversion rate of about $33 \%$ in the digital market. Do not feel that agency operates niche. The better the agency execute, the more the chance of getting clients. 


\section{CONCLUSION}

This study clears gives a short note on how do media agencies work for their client companies. What are the types of procedures they do follow with the clients and competitors. As per 2011 report, there were only 50 social media companies and it has grown up to 700 in 2019 . The study has noted the problems faced by the media agencies; also few suggestions have been penned. This would be a useful paper for those agencies who wants to move up in their business.

\section{REFERENCES}

1. https://ads.google.com/intl/en in/home/res ources/internet-marketing/

2. https://www.wordstream.com/socialmedia-marketing

3. https://www.webkick.co.uk/blog/commonproblems-with-social-media-marketinghow-to-overcome-them

4. https://digitalagencynetwork.com/how-tostart-a-social-media-marketing-agency/

5. https://www.forbes.com/sites/robertadams/ 2017/04/27/what-is-online-marketing-thedefinitive-guide-to-internetvisibility/\#6eeec9c9377f

6. https://www.wrike.com/blog/beginnersguide-to-online-marketing-free-ebook/

7. https://www.soravjain.com/indian-socialmedia-digital-marketing-agencies/

8. http://www.socialsamosa.com/2019/01/ind ian-marketing-agencies-1000-plus-list/ 